\title{
Stress-opioid interactions: a comparison of morphine and methadone
}

\author{
Ewa Taracha ${ }^{1}$, Paweł Mierzejewski ${ }^{2}$, Małgorzata Lehner ${ }^{1}$, \\ Stanisław J. Chrapusta ${ }^{3}$, Maria Kała ${ }^{4}$, Wojciech Lechowicz ${ }^{4}$, \\ Adam Hamed $^{5}$, Anna Skórzewska ${ }^{1}$, Wojciech Kostowski ${ }^{2}$, Adam Płaźnik ${ }^{1,5}$ \\ ${ }^{1}$ Department of Neurochemistry, Institute of Psychiatry and Neurology, Sobieskiego 9, PL 02-957 Warszawa, \\ Poland \\ ${ }^{2}$ Department of Pharmacology and Physiology of the Nervous System, Institute of Psychiatry and Neurology, \\ Sobieskiego 9, PL 02-957 Warszawa, Poland \\ ${ }^{3}$ Department of Experimental Pharmacology, Mossakowski Medical Research Center, Polish Academy of Sciences, \\ Pawińskiego 5, PL 02-106 Warszawa, Poland \\ ${ }^{4}$ Institute of Forensic Research, Westerplatte 9, PL 31-033 Kraków, Poland \\ ${ }^{5}$ Department of Experimental and Clinical Pharmacology, Medical University of Warsaw, Krakowskie \\ Przedmieście 26/28, PL 00-927 Warszawa, Poland \\ Correspondence: Ewa Taracha, e-mail: taracha@ipin.edu.pl
}

\begin{abstract}
:
The utility of methadone and morphine for analgesia and of methadone for substitution therapy for heroin addiction is a consequence of these drugs acting as opioid receptor agonists. We compared the cataleptogenic and antinociceptive effects of single subcutaneous doses of methadone hydrochloride ( $1-4 \mathrm{mg} / \mathrm{kg})$ and morphine sulfate $(2.5-10 \mathrm{mg} / \mathrm{kg})$ using catalepsy and hot-plate tests, and examined the effects of the highest doses of the drugs on Fos protein expression in selected brain regions in male Sprague-Dawley rats. Methadone had greater cataleptogenic and analgesic potency than morphine. Fos immunohistochemistry revealed substantial effects on the Fos response of both the stress induced by the experimental procedures and of the drug exposure itself. There were three response patterns identified: 1) drug exposure, but not stress, significantly elevated Fos-positive cell counts in the caudate-putamen; 2) stress alone and stress combined with drug exposure similarly elevated Fos-positive cell counts in the nucleus accumbens and cingulate cortex; and 3) methadone and morphine (to a lesser extent) counteracted the stimulatory effect of nonpharmacological stressors on Fos protein expression in the somatosensory cortex barrel field, and Fos-positive cell counts in this region correlated negatively with both the duration of catalepsy and the latency time in the hot-plate test. The overlap between brain regions reacting to nonpharmacological stressors and those responding to exogenous opioids suggests that stress contributes to opioid-induced neuronal activation.
\end{abstract}

\section{Key words:}

opioid, stress, Fos protein, striatum, nucleus accumbens, cortex, catalepsy, pain 


\begin{abstract}
Abbreviations: $\mathrm{Acb}$ - nucleus accumbens $(\mathrm{AcbC}$ - core, AcbSh - shell), ANOVA - analysis of variance, CG - cingulate cortex, $\mathrm{CPu}$ - caudate-putamen, HPLC - high performance liquid chromatography, IS - internal standard, LC-MS - combined liquid chromatography-mass spectrometry, Meth - methadone, Morph - morphine, MOR $-\mu$ opioid receptor, NDS - normal donkey serum, S1BF - somatosensory cortex barrel field; S1JO - primary somatosensory cortex (jaw region, oral part), $\mathrm{Sal}-0.9 \% \mathrm{NaCl}$
\end{abstract}

\section{Introduction}

It is established that morphine (Morph), which is a high-affinity agonist of the opioid receptor (MOR) and one of the most addictive drugs, is also one of the most potent analgesics. Interestingly, brain regions activated by various stressors, such as pain, overlap with those that contribute to the development of addiction to psychoactive drugs $[7,22]$. It is believed that the latter phenomenon is promoted by various stressors (reviewed in [22]), including environmental novelty $[4,14]$.

Methadone (Meth), which is a synthetic highaffinity MOR agonist, and Morph show distinct activity profiles in various experimental models and in clinical practice. Meth exerts several typical opiate effects including analgesia, immunomodulatory effects, respiratory suppression, and modification of sleep patterns $[11,18,39]$. The different molecular, cellular and behavioral characteristics of Meth and Morph dictate which to prescribe in a specific clinical situation. From a clinical point of view, the most important difference is the considerably lower euphoric and addictive potential of Meth and the much slower development of tolerance to this drug with long-term use. These characteristics allow the safe use of Meth for the attenuation of detoxification-associated signs of abstinence syndrome and long-term substitution therapy in opiate drug (mostly heroin) addicts. Meth is also an effective analgesic in a considerable subset of Morph-resistant patients [28]. In contrast to Morph, it is not converted to active metabolites in vivo, but is cleared at a considerably slower rate so it can accumulate in tissues after repeated administration. The latter characteristic makes Meth riskier to use than Morph [38] and renders Meth a second choice analgesic that is used predominantly when other MOR agonists are ineffective, or when tolerance develops [9].
The advantages of Meth have been ascribed to its considerably higher ability to induce MOR desensitization or internalization, as compared to Morph [19, 25], and its longer half-life in vivo, as compared to that of heroin or its active metabolites (Morph and 6-monoacetylmorphine) [1, 29]. The longer half-life enables dosing of Meth at much longer time intervals than those between consecutive heroin doses selfadministered by heroin addicts. This characteristic helps to stabilize physiologic processes compromised by heroin abuse, e.g. the centrally regulated circadian rhythms of the thalamo-pituitary axis [20].

In laboratory settings, Morph is used much more frequently than heroin to model specific aspects of opiate addiction. Exploring pharmacological differences between Morph and Meth in animal models in the context of other factors, such as mild stress, that are relatively harmless themselves but can promote the development of addiction in humans, is interesting with regard to both analgesia and drug addiction. The data generated by these studies may aid in the development of improved therapeutic modalities for the treatment of pain and addiction.

The main goal of this study was to compare the effects of Morph and Meth in the context of experimentallyinduced stress. This interaction was assessed by neuronal activation, as measured by Fos-positive cell counts, in various brain regions including those considered essential for the development of addiction.

\section{Materials and Methods}

\section{Animals}

The study was performed in adult male SpragueDawley rats from the PAS Medical Research Center stock. The starting body weight mean \pm SD was 176 $\pm 15 \mathrm{~g}$. The rats were housed four or five to an opaque plastic cage $(35 \times 56 \mathrm{~cm}$ floor size $)$ in an air-conditioned room $\left(21 \pm 2^{\circ} \mathrm{C}, 60-70 \%\right.$ relative humidity) with a 12/12 h light/dark cycle (lights on at 7:00 a.m.). The rats were allowed standard rodent chow and tap water ad libitum. All animal use procedures were in compliance with the NIH Guide for the Care and Use of Laboratory Animals and were accepted by the Bioethical Committee of the Medical University of Warsaw. 


\section{Chemicals}

(R,S)-methadone hydrochloride was donated by Molteni Farmaceutici (Scandicci, Italy), and morphine sulfate was purchased from Polfa (Warszawa, Poland). Drug standards and deuterated internal standards (ISs: $\left[{ }^{2} \mathrm{H}_{3}\right]$ Morph and $\left[{ }^{2} \mathrm{H}_{3}\right]$ Meth) for combined liquid chromatography-mass spectrometry (LC-MS) analyses were supplied by Cerilliant Corp. (Round Rock, TX, USA). The rabbit polyclonal anti-c-Fos antibody [anti-c-Fos (Ab-2) (4-17) rabbit IgG] was from Calbiochem (San Diego, CA, USA); its specificity was verified as recommended by the manufacturer (see Calbiochem Data Sheet PP10 Rev. 15-April-04 $\mathrm{DCH}$ ). Normal donkey serum (NDS) was purchased from Jackson Immuno-Research Labs (West Grove, PA, USA), and avidin-biotin-peroxidase complex and biotinylated goat anti-rabbit IgGs were obtained from Vector Labs (Burlingame, CA, USA). DePeX mounting medium was from VWR International Ltd. (Poole, England), heparin and sterile $\mathrm{NaCl}$ 0.9\% (Sal) were from Polfa Warszawa SA (Warszawa, Poland), and ketamine hydrochloride was from Gedeon Richter (Budapest, Hungary). Acetonitrile and ethyl acetate (both HPLC grade) were purchased from Merck, (Darmstadt, Germany), and formic acid (analytical grade, 91\%) was from Ubichem (Chandlers Ford, U.K.). All other chemicals were of analytical grade and were purchased from ChemPur (Piekary Śląskie, Poland), POCh (Gliwice, Poland), Serva (Heidelberg, Germany), and Merck (Darmstadt, Germany). The aqueous solutions used for liquid chromatographymass spectrometry analyses and other procedures were made with bi-distilled water from a quartz apparatus and MilliQ-deionized water, respectively.

\section{Experimental design}

The opioid dose ranges were similar to those used by us and others in previous studies [9, 37]. The drugs were dissolved in Sal to give injection volumes of $0.5 \mathrm{ml} / \mathrm{kg}$, and control rats were injected with the same volume of Sal. The 3-step cross-over experimental paradigm is shown in Table 1. After sacrificing the rats, their brains were quickly removed, snapfrozen in cold $\left(-79^{\circ} \mathrm{C}\right)$ isopentane, and stored at $-70^{\circ} \mathrm{C}$ for Fos immunohistochemical processing. Drug-free blood samples used for the development of the LC-MS assays for Morph and Meth were taken from intact controls (Table 1). Two additional groups of four rats were used for the assessment of Meth and Morph half-lives after a single sc drug dose. These rats were first subjected to catheter implantation (see below).

\section{Catalepsy and antinociception testing and body temperature measurement}

Catalepsy was evaluated 20 min after the injection of Morph, Meth, or Sal into the rats, by gently positioning both forepaws on a wooden bar ( $5 \mathrm{~mm}$ diameter) placed horizontally $9 \mathrm{~cm}$ above the working surface, and measuring the time to move at least one paw off the bar. The cut-off time was $180 \mathrm{~s}$ [6].

Body temperature was measured with a model TE 3.S digital thermometer (Ellab Instruments, Roedovre, Denmark) immediately after completion of the catalepsy test, i.e. 21-23 min after the injection of drug or vehicle. An electric thermocouple was inserted $3 \mathrm{~cm}$ deep into the rectum and allowed to stabilize for $30 \mathrm{~s}$ before recording the temperature [32], while the rat was gently immobilized (head down).

Antinociception was assessed using an HP01 hot plate instrument (COTM, Białystok, Poland) with the plate temperature maintained at $56 \pm 0.1^{\circ} \mathrm{C}$. The rat was placed with all four paws on the plate, and the latency time to licking or shaking a hind limb was measured. The cut-off time was set at $30 \mathrm{~s}$ to avoid tissue damage.

\section{Catheter implantation}

Chronic catheters were implanted into the right jugular vein under ketamine-xylazine anesthesia as previously described [27]. The rats were allowed one week of recovery from the surgery before pharmacokinetic testing. To maintain patency, the catheters were flushed daily with $0.5 \mathrm{ml}$ of heparin-supplemented (5 IU/ml) Sal during the recovery period.

\section{Pharmacokinetic testing}

Experimentally naive rats were administered morphine sulfate $(10 \mathrm{mg} / \mathrm{kg}, s c)$ or $(\mathrm{R}, \mathrm{S})$-methadone hydrochloride (4 mg/kg, sc). The choice of the doses was dictated by the fact that these drug doses were used for the study of Fos protein response. Blood samples $(200 \mu \mathrm{l})$ were taken via the implanted catheters $5,10,20,45,75,120$ and 180 min post-injection 
Tab. 1. Experimental design

\begin{tabular}{|c|c|}
\hline Experiment day & Procedure \\
\hline $\begin{array}{c}0 \\
\text { (Rats' arrival day) }\end{array}$ & Weighing and randomization between experimental groups ( $\mathrm{N}=9$ for each group) \\
\hline $1-8$ & $\begin{array}{l}\text { All groups: Acclimation to the local animal facility environment and habituation to brief (about } 1 \mathrm{~min} \text { ) daily handling by the } \\
\text { experimental personnel }\end{array}$ \\
\hline 9 & $\begin{array}{l}\text { Treatment step } \mathrm{I}^{\mathrm{a}} \\
\text { Group } 1 \text { (Morph/Meth/Sal): morphine sulfate } 5 \mathrm{mg} / \mathrm{kg} \text {, sc } \\
\text { Group } 2 \text { (Sal/Morph/Meth): NaCl 0.9\% } 0.5 \mathrm{ml} / \mathrm{kg}, \mathrm{sc} \\
\text { Group } 3 \text { (Meth/Sal/Morph): (R,S)-methadone hydrochloride } 2 \mathrm{mg} / \mathrm{kg}, s c \\
\text { Groups } 1-3 \text { (20 min after the injection): Catalepsy test, rectal temperature measurement, hot-plate test (in this order) } \\
\text { Group } 4 \text { (intact controls): brief handling }\end{array}$ \\
\hline $10-20$ & Wash-out period, no treatment \\
\hline 21 & $\begin{array}{l}\text { Treatment step } \| \\
\text { Group } 1 \text { (Morph/Meth/Sal): (R,S)-methadone hydrochloride } 1 \mathrm{mg} / \mathrm{kg}, \mathrm{sc} \\
\text { Group } 2 \text { (Sal/Morph/Meth): morphine sulfate } 2.5 \mathrm{mg} / \mathrm{kg}, s c \\
\text { Group } 3 \text { (Meth/Sal/Morph): NaCl } 0.9 \% 0.5 \mathrm{ml} / \mathrm{kg}, \mathrm{sc} \\
\text { Groups } 1-3 \text { (20 min after the injection): Catalepsy test, rectal temperature measurement, hot-plate test (in this order) } \\
\text { Group } 4 \text { (intact controls): brief handling }\end{array}$ \\
\hline 22-32 & Wash-out period, no treatment \\
\hline 33 & $\begin{array}{l}\text { Treatment step } \| \\
\text { Group } 1 \text { (Morph/Meth/Sal): NaCl 0.9\% } 0.5 \mathrm{ml} / \mathrm{kg}, s c \\
\text { Group } 2 \text { (Sal/Morph/Meth): (R,S)-methadone hydrochloride } 4 \mathrm{mg} / \mathrm{kg}, \mathrm{sc} \\
\text { Group } 3 \text { (Meth/Sal/Morph): morphine sulfate } 10 \mathrm{mg} / \mathrm{kg}, s c \\
\text { Groups } 1-3 \text { (20 min after the injection): Catalepsy test, rectal temperature measurement, hot-plate test (in this order). Two } \\
\text { hours after the sc injection, the rats were sacrificed via simple decapitation (with no perfusion) when deeply anesthetized with an } \\
\text { ip dose of a mixture of pentobarbital and sodium pentobarbital (Morbital, Biowet, Puławy, Poland; } 200 \mathrm{mg} / \mathrm{kg} \text { ) given } 3 \text { min prior } \\
\text { to sacrifice }{ }^{b} \text {. } \\
\text { Group } 4 \text { (intact controls): no testing or pharmacological treatment. The rats were sacrificed by simple decapitation when } \\
\text { anesthetized as above, and their trunk blood was used for the development and validation of LC-MS assays for Morph and Meth. }\end{array}$ \\
\hline
\end{tabular}

a Abbreviations in parentheses show the full sequence of pharmacological treatment steps I-III for a given group; Morph = morphine sulfate, Meth $=(R, S)$-methadone hydrochloride, Sal $=0.9 \% \mathrm{NaCl}$. ${ }^{b}$ One rat in group 3 died shortly after performing the tests; its brain was not processed for Fos immunocytochemistry and step III tests' results for the rat were excluded from statistical analyses

and were immediately frozen at $-70^{\circ} \mathrm{C}$ pending analysis.

\section{Blood processing for LC-MS analysis}

Blood samples were thawed and then sonicated for $15 \mathrm{~min}$ in an ultrasonic bath at room temperature. Aliquots $(100 \mu \mathrm{l})$ of the solubilized blood samples were placed in $2 \mathrm{ml}$ tubes and $20 \mu \mathrm{l}$ of methanolic solution of deuterated ISs (40 ng each), $300 \mu \mathrm{l}$ of $0.9 \mathrm{M}$ sodium carbonate buffer $\mathrm{pH} 9.0$, and $1.2 \mathrm{ml}$ of ethyl acetate were added to each tube. Calibration curve samples were made by spiking sonicated control blood samples with Morph and Meth to yield 0, 0.01, 0.1, 0.2, $0.5,1,2,5$ and $10 \mu \mathrm{g} / \mathrm{ml}$ of each analyte. All tubes were capped and vigorously vortexed for $1 \mathrm{~min}$. After centrifugation at $6000 \times \mathrm{g}$ for $3 \mathrm{~min}, 1 \mathrm{ml}$ aliquots of the upper phase were transferred to $1.8 \mathrm{ml}$ tubes and evaporated to dryness under a stream of nitrogen. The dry residues were dissolved in $100 \mu \mathrm{l}$ aliquots of aqueous $0.09 \%$ formic acid for analysis. Extraction yields for all analytes were $\geq 60 \%$.

\section{LC-MS analyses}

LC-MS analyses were run on an HP-1100 series LC chromatograph equipped with an autosampler and a model LiChroCART Purospher START RP-18e column (55 mm $\times 4 \mathrm{~mm}$ I.D., Merck) and coupled to a mass-selective detector equipped with an atmospheric pressure chemical ionization source (Agilent Technologies, Wilmington, DE, USA). The mobile phase was $0.09 \%$ formic acid in water (A) and in acetonitrile (B). The gradient employed was as follows 
(regarding component $\mathrm{B}$ ): $\mathrm{t}=0 \mathrm{~min}-5 \%, \mathrm{t}=7 \mathrm{~min}-$ $50 \%, \mathrm{t}=8 \mathrm{~min}-5 \%$, and then constant for $3 \mathrm{~min}$; the flow rate was $0.8 \mathrm{ml} / \mathrm{min}$.

The ionization source was operated in positive ionization mode with nitrogen as the ionization gas. MS parameters were optimized using flow injection analysis to select the most intense ion signals. The main settings were as follows: fragmentor voltage, $60 \mathrm{~V}$; capillary voltage, $4000 \mathrm{~V}$; vaporizer temperature, $300^{\circ} \mathrm{C}$; coronal current, $4.5 \mu \mathrm{A}$; and drying gas flow rate, $5.0 \mathrm{l} / \mathrm{min}$. Drugs were identified by their retention time and the presence of a qualifier ion and a quantitative ion. Mass-to-charge ratios for the quantitative ions (pseudomolecular ions, which were chosen by abundance and lack of baseline interference) used for measuring Morph, $\left[{ }^{2} \mathrm{H}_{3}\right]$ Morph, Meth and $\left[{ }^{2} \mathrm{H}_{3}\right]$ Meth were 286, 289, 310 and 313, respectively.

Standardization was carried out using the respective deuterated ISs. Calibration was performed by linear (least-squares) regression analysis. Peak area ratios for the target analytes and their respective ISs were obtained with the Agilent software v.A.06.03. The limit of detection was determined as the lowest detectable concentration with a minimum signal-tonoise ratio of 3 and retention time within $0.1 \mathrm{~min}$ of the calibration standard. The cut-off limits for detection and quantitation (signal-to-noise ratio of 10) were 2 and $10 \mathrm{ng} / \mathrm{ml}$, respectively, and the ranges of linearity were 0.01 to $10 \mu \mathrm{g} / \mathrm{ml}$ for both drugs.

\section{Fos immunohistochemistry}

After decapitation (with no perfusion, see [23, 36, $44]$ ), the brains were instantly removed, snap-frozen in cold $\left(-79^{\circ} \mathrm{C}\right)$ isopentane and stored at $-79^{\circ} \mathrm{C}$ until further processing. A detailed description of the Fos protein immunohistochemistry-related procedures has been previously published [36, 44]. Briefly, for each region studied, two adjacent coronal $18 \mu \mathrm{m}$ cryoslices were cut from each brain based on the rat brain atlas [31]. They were mounted on silanized glass slides, fixed in cold methanol, washed with phosphatebuffered $0.9 \% \mathrm{NaCl}$ (PBS), incubated with methanolic $\mathrm{H}_{2} \mathrm{O}_{2}$ solution, washed again with PBS and incubated with NDS solution in PBS. Next, the slices were incubated with diluted (1:2000) rabbit anti-c-Fos IgG solution in NDS-supplemented PBS, washed with PBS, incubated with biotinylated goat anti-rabbit IgGs supplemented with NDS, and washed again with PBS. Then they were incubated with avidin-biotinperoxidase complex according to the manufacturer's instructions, washed with Tris- $\mathrm{HCl}$ buffer $\mathrm{pH}$ 7.4, and next incubated with 3,3'-diaminobenzidine tetrahydrochloride $/ \mathrm{H}_{2} \mathrm{O}_{2}$ solution in the same buffer. The reaction was stopped by washing the slices with deionized water. Finally, the slices were dehydrated with a standard ethanol dilution series and coverslipped with DePeX. Fos immunostaining was quantitated at $40 \times$ magnification by a researcher
Bregma +2.20

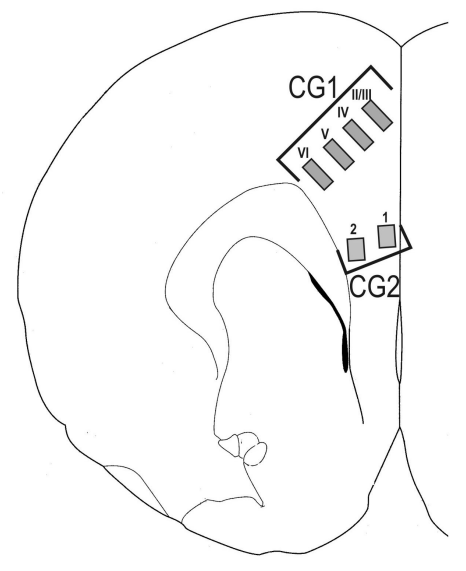

\section{Bregma +1.70}

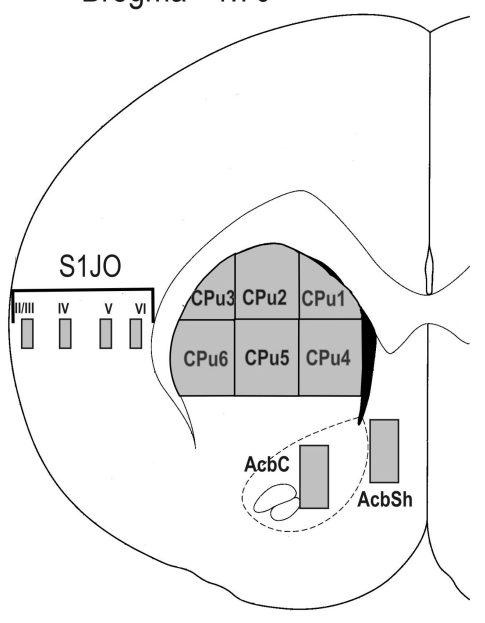

Bregma -3.30

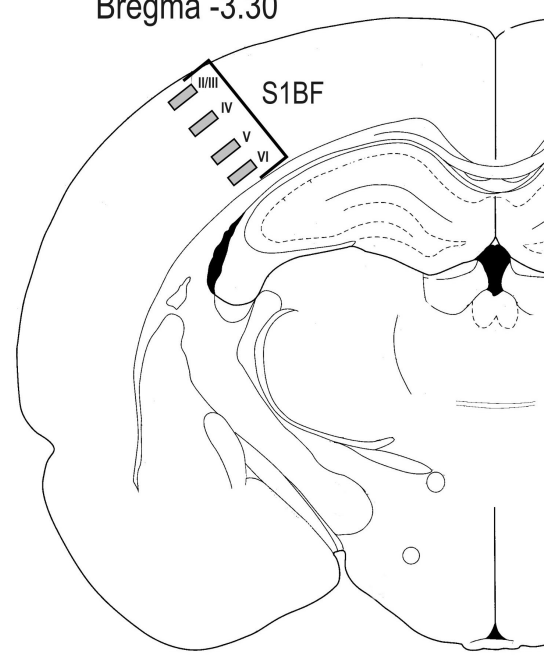

Fig. 1. Drawings of brain cross-sections (adapted from Paxinos and Watson, [31], with permission) with the locations of fields analyzed by Fos immunohistochemistry. The cingulate cortex areas 1 and 2 (CG1 and CG2, respectively), primary somatosensory cortex (jaw region, oral part, $\mathrm{S} 1 \mathrm{JO}$ ) and somatosensory cortex barrel region (S1BF) fields were $0.1 \mathrm{~mm}^{2}$ each. The nucleus accumbens' fields (core - AcbC, shell - AcbSh) were $0.5 \mathrm{~mm}^{2}$ each, and the caudate-putamen (CPu) fields were as shown in the middle panel 
blinded to the slices' identity, using an Olympus BX-51 microscope equipped with a DP-70 Olympus camera and computerized analysis system (Cell* Imaging Software for Life Sciences, Soft Imaging System Ltd., Münster, Germany). The counts were averaged for the twin slices and brain sides. Cortical layer I, which showed no presence of neuronal somata or Fos expression, was excluded from the study, and Fos-positive nuclei in layers II and III were counted jointly. The locations of brain fields used for the assessment of Fos immunostaining are shown in Fig. 1.

\section{Data analysis}

The half-lives of drugs were computed by regression analysis of the respective blood levels assessed by LC-MS, assuming first order kinetics. Catalepsy, hotplate test data and Fos-positive cell counts were analyzed using Kruskal-Wallis ANOVA by ranks followed by the Mann-Whitney $U$ test or the nonparametric test of multiple comparisons as appropriate. Correlations between the nociception and catalepsy test data and the Fos immunostaining data were analyzed using Spearman's rank correlation test. In all cases, a $\mathrm{p} \leq 0.05$ was considered significant. All the analyses were run with the Statistica software v.7.1 (StatSoft Inc., Tulsa, OK, USA).

\section{Results}

\section{Pharmacokinetic studies}

The highest blood levels of Meth and Morph were observed $5 \mathrm{~min}$ post-injection. The analysis of blood drug levels between 5 and $180 \mathrm{~min}$ post-injection in rats given single subcutaneous doses of the opioids yielded $\tau_{1 / 2}=37.0 \mathrm{~min}(95 \% \mathrm{CI}: 27.3-57.7 \mathrm{~min})$ and $\tau_{1 / 2}=80.1 \mathrm{~min}$ (95\% CI: 54.9-147.6 min), for Morph and Meth, respectively. These data were consistent with previous reports [24].

\section{Catalepsy, body temperature and antinociception study}

There was no significant difference in body weight between the study groups on the last day of the experiment $\left(\mathrm{F}_{4,32}=0.75, \mathrm{p}=0.53\right)$.
There was no effect on body temperature 21-23 $\mathrm{min}$ after injection of Morph or Meth (results not shown). It is possible that the elapsed time since injection was insufficient for the emergence of hypothermia [6].

Both drugs significantly increased both catalepsy and hot-plate test latency time, except that at the lowest dose tested, the only significant increase was ob-
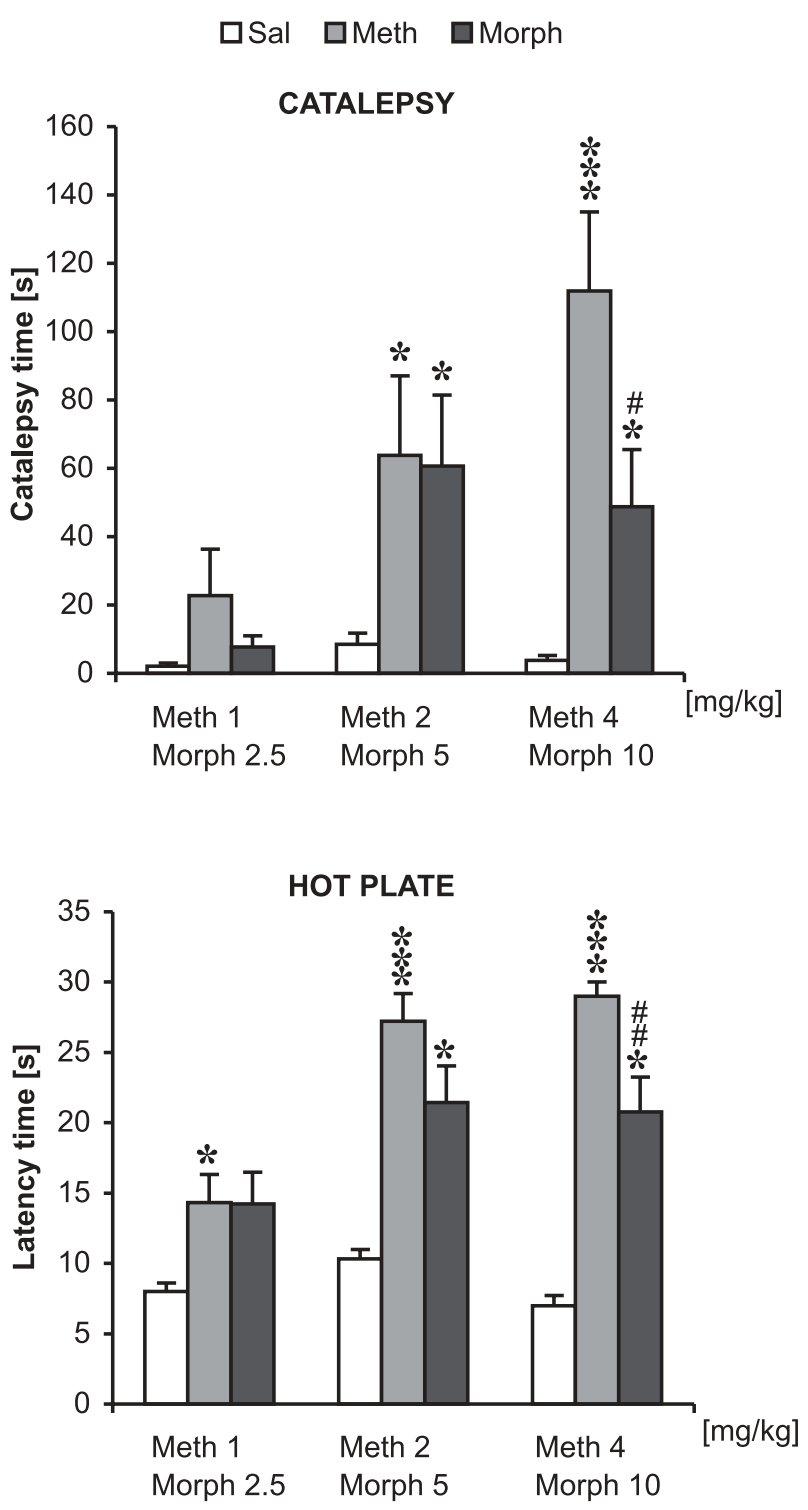

Fig. 2. The effects of subcutaneous doses of morphine (Morph) and methadone (Meth) on catalepsy score (upper panel) and nociception (hot plate test, lower panel) in male rats. Results shown are the mean $\pm S D ;{ }^{*} p<0.05,{ }^{* * *} p<0.001$ versus the corresponding saline-injected (Sal) group value (by the nonparametric multiple comparisons' test); $\# p<0.05, \# p<0.01$ versus the respective group injected with Meth (Mann-Whitney $U$ test). Please note that most of the results are from rats given one or two opioid dose some days earlier - refer to Table 1 for experimental details 
served in the hot-plate test latency time with Meth treatment (Fig. 2). No test cut-off value was reached by any rat given the lowest dose of either Morph $(2.5 \mathrm{mg} / \mathrm{kg})$ or Meth $(1 \mathrm{mg} / \mathrm{kg})$. Two and four out of nine rats given the medium $(2 \mathrm{mg} / \mathrm{kg})$ and the highest (4 $\mathrm{mg} / \mathrm{kg}$ ) dose of Meth, respectively, reached the cut-off limit for the catalepsy test, and six and eight out of those rats, respectively, reached the latency time cut-off limit for the hot-plate test. In contrast, none of the rats given the medium Morph dose $(5 \mathrm{mg} / \mathrm{kg})$, and only one out of nine rats given the highest Morph dose $(10 \mathrm{mg} / \mathrm{kg})$ reached the cut-off limit for the catalepsy test. Only two rats in each of these groups reached the cut-off limit for the hot-plate test. At the highest doses tested, the responses evoked by methadone hydrochloride were significantly greater than those induced by 2.5 -fold higher doses of morphine sulfate (based on mass).

\section{Fos immunohistochemistry}

Representative microphotographs of Fos immunohistochemistry are shown in Fig. 3 and the results are summarized in Table 2.

Cingulate cortex (CG): The Fos immunostaining in rats injected with Morph or Meth did not differ significantly from that in their Sal-injected counterparts, but both these groups showed significantly higher Fos-positive cell counts than the intact control group in all CG fields studied.

Primary somatosensory cortex (jaw region, oral part; S1JO): Fos-positive cell counts in layer VI of the Morph- or Meth-injected rats, layer $\mathrm{V}$ of the
Morph-injected rats and layer II/III of the Methinjected rats were significantly higher than those in the corresponding cortical layers of the intact controls. No other significant between-group difference was observed in this region.

Primary somatosensory cortex, barrel field (S1BF): All layers studied in this region showed significantly higher Fos-positive cell counts in the Sal-injected rats compared to the intact controls. Layers II/III and IV in the Meth-injected rats and layer II/III in the Morphinjected rats also showed significantly lower Fospositive counts than the respective brain regions of the Sal-injected rats. Apart from layer VI in the Morph-injected rats, there was no statistically significant difference in Fos counts in any S1BF layer between the intact controls and the opioid-injected rat groups. There was a significant negative correlation between the Fos immunostaining in S1BF layers II/III-V and the results of either the catalepsy test (Spearman's correlation coefficient, respectively, $\mathrm{R}=$ $-0.78, \mathrm{R}=-0.85$ and $\mathrm{R}=-0.52$ ) or the hot-plate test $(\mathrm{R}=-0.69, \mathrm{R}=-0.75$ and $\mathrm{R}=-0.60$, respectively).

Nucleus accumbens shell (AcbSh) and core $(A c b C)$ : Both these regions showed significantly less Fos immunostaining in the intact controls as compared to the other groups, whereas there was no difference in Fos immunostaining in these regions between the rats given Sal and those given Morph or Meth on the last day of the experiment.

Caudate-putamen (CPu): All studied parts of this region, except for $\mathrm{CPu} 4(\mathrm{p}=0.08)$, showed significantly higher Fos immunostaining in the rats injected with Morph $2 \mathrm{~h}$ before sacrifice as compared to their
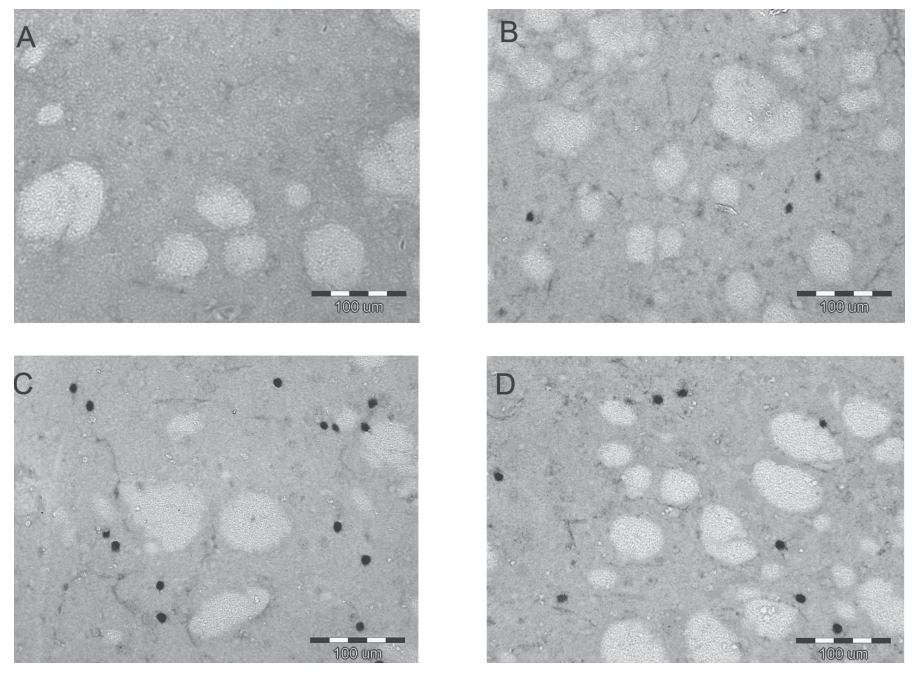

Fig. 3. Representative microphotographs of striatal Fos immunohistochemistry in nonperfused brains from an intact rat (panel A) and from a saline- (panel B), morphine- $(10 \mathrm{mg} / \mathrm{kg}$, panel C) or methadone-injected (4 mg/kg, panel D) rat. Please note that the rats, except for the intact one, were given one or two opioid doses some days earlier; refer to Table 1 for details. All the microphotographs were taken at 200 magnification 
Tab. 2. Fos-positive cell nuclei counts $\left(\mathrm{N} / \mathrm{mm}^{2}\right.$; mean $\left.\pm \mathrm{SD}\right)$ in selected brain fields of rats given sc injections of morphine sulfate (Morph), methadone hydrochloride (Meth) and $\mathrm{NaCl} 0.9 \%$ (Sal), and subjected to catalepsy testing, rectal temperature measurement and hot plate testing $2 \mathrm{~h}$ prior to sacrifice for Fos immunocytochemistry, and in experimentally naive controls ${ }^{\mathrm{a}}$

\begin{tabular}{|c|c|c|c|c|c|}
\hline \multirow[t]{2}{*}{ Brain field } & \multirow[t]{2}{*}{ Kruskal-Wallis ANOVA } & \multicolumn{4}{|c|}{ Treatment } \\
\hline & & $\begin{array}{c}\text { Intact controls } \\
\mathrm{N}=9\end{array}$ & $\begin{array}{c}\text { Morph/Meth/Sal } \\
N=9\end{array}$ & $\begin{array}{c}\text { Meth/Sal/Morph } \\
\quad N=8\end{array}$ & $\begin{array}{c}\text { Sal/Morph/Meth } \\
\qquad N=8^{b}\end{array}$ \\
\hline CG1_I/III & $H_{3, N}=33=16.5, p=0.0009$ & $9.4 \pm 26.5$ & $108.9 \pm 44.1^{\#}$ & $141.9 \pm 106.8^{\#}$ & $94.4 \pm 53.3^{\#}$ \\
\hline CG1_IV & $H_{3, N}=33=17.1, p=0.0007$ & $4.4 \pm 12.4$ & $81.7 \pm 27.0^{\#}$ & $103.1 \pm 63.5^{\#}$ & $85.0 \pm 54.6^{\#}$ \\
\hline CG1_V & $H_{3, N}=33=18.1, p=0.0004$ & $3.1 \pm 8.8$ & $105.6 \pm 42.7^{\#}$ & $126.3 \pm 57.5^{\#}$ & $116.9 \pm 48.7^{\#}$ \\
\hline CG1_VI & $H_{3, N}=33=17.6, p=0.0005$ & $8.1 \pm 15.8$ & $99.4 \pm 37.1^{\#}$ & $110.6 \pm 62.0^{\#}$ & $116.3 \pm 39.7^{\#}$ \\
\hline CG2_1 & $H_{3, N}=33=18.8, p=0.0003$ & $3.1 \pm 5.3$ & $138.9 \pm 47.6^{\# \# \#}$ & $114.4 \pm 62.0^{\#}$ & $105.0 \pm 59.9^{\#}$ \\
\hline CG2_2 & $H_{3, N}=33=17.9, p=0.0005$ & $8.8 \pm 15.8$ & $141.7 \pm 39.8^{\#}$ & $158.8 \pm 72.6^{\#}$ & $134.4 \pm 55.3^{\#}$ \\
\hline S1JO_II/II & $H_{3, N}=34=13.0, p=0.0047$ & $0.6 \pm 1.7$ & $5.8 \pm 7.0$ & $4.4 \pm 5.3$ & $9.1 \pm 7.1^{\#}$ \\
\hline S1JO_IV & $H_{3, N=34}=9.2, p=0.026$ & $0.0 \pm 0.0$ & $8.1 \pm 10.2$ & $10.9 \pm 25.0$ & $13.4 \pm 15.3$ \\
\hline S1J0_V & $H_{3, N}=34=11.6, p=0.009$ & $0.0 \pm 0.0$ & $6 \pm 9.9$ & $17.2 \pm 20.7^{\#}$ & $8.4 \pm 9.3$ \\
\hline S1JO_VI & $H_{3, N}=34=23.8, p<10^{-4}$ & $0.3 \pm 0.8$ & $19.7 \pm 15.5$ & $64.1 \pm 37.5^{\# \# \#}$ & $38.8 \pm 28.4^{\#}$ \\
\hline S1BF_II/II & $H_{3, N}=32=19.0, p=0.0003$ & $6.9 \pm 7.0$ & $67.8 \pm 54.3^{\#}$ & $10.6 \pm 13.3^{\star}$ & $3.9 \pm 5.6^{\star \star \star}$ \\
\hline S1BF_IV & $H_{3, N}=32=22.6, p<10^{-4}$ & $4.4 \pm 3.5$ & $111.1 \pm 69.3^{\# \# \#}$ & $13.1 \pm 6.1$ & $9.6 \pm 10.4^{*}$ \\
\hline S1BF_V & $H_{3, N}=32=13.7, p=0.0033$ & $7.5 \pm 8.1$ & $48.3 \pm 21.7^{\#}$ & $20.0 \pm 14.3$ & $18.6 \pm 13.7$ \\
\hline S1BF_VI & $H_{3, N}=32=14.4, p=0.0024$ & $17.5 \pm 23.1$ & $85.8 \pm 37.5^{\#}$ & $76.3 \pm 33.4^{\#}$ & $54.3 \pm 17.0$ \\
\hline AcbC & $H_{3, N}=34=17.1, p=0.0007$ & $7.3 \pm 9.9$ & $46.7 \pm 32.8^{\#}$ & $38.3 \pm 14.1^{\#}$ & $44.1 \pm 11.6^{\#}$ \\
\hline AcbSh & $H_{3, N}=34=16.2, p=0.001$ & $11.3 \pm 16.8$ & $62.9 \pm 35.3^{\#}$ & $68.6 \pm 30.5^{\#}$ & $61.0 \pm 15.3^{\#}$ \\
\hline CPu1 & $H_{3, N}=34=28.7, p<10^{-4}$ & $0.6 \pm 1.8$ & $16.7 \pm 12.4$ & $85.2 \pm 16.3^{\# \#, *}$ & $61.4 \pm 24.0^{\# \# \#}$ \\
\hline CPu2 & $H_{3, N}=34=26.3 p<10^{-4}$ & $0.8 \pm 2.4$ & $7.3 \pm 8.3$ & $36.6 \pm 16.8^{\# \# \#, *}$ & $22.6 \pm 12.4^{\#}$ \\
\hline CPu3 & $H_{3, N=34}=21.1, p<10^{-4}$ & $0.5 \pm 1.4$ & $2.2 \pm 2.8$ & $11.3 \pm 14.3^{\# \#, *}$ & $3.2 \pm 1.9$ \\
\hline CPu4 & $H_{3, N}=34=24.3, p<10^{-4}$ & $1.0 \pm 3.1$ & $10.4 \pm 10.3$ & $32.9 \pm 13.0^{\# \# \#}$ & $22.5 \pm 9.4^{\#}$ \\
\hline CPu5 & $H_{3, N}=34=20.3, p=0.0001$ & $0.2 \pm 0.6$ & $1.7 \pm 2.8$ & $6.3 \pm 3.5^{\# \#, \star \star}$ & $4.5 \pm 4.7^{\#}$ \\
\hline CPu6 & $H_{3, N}=34=19.2, p=0.0002$ & $0.1 \pm 0.2$ & $0.1 \pm 0.3$ & $3.2 \pm 2.8^{\#, *}$ & $1.9 \pm 2.5^{\#}$ \\
\hline
\end{tabular}

a For experimental details see Table $1 ;{ }^{b}$ except for S1BF, $N=7 .{ }^{*} p<0.05,{ }^{\star \star *} p<0.001$ vs. the respective Morph/Meth/Sal value; ${ }^{\#} p<0.05$, $\# \#$ $\quad$ \& 0.001 vs. the respective intact controls' value (by the nonparametric multiple comparisons test)

Sal-injected counterparts or intact controls. There was no difference in Fos immunostaining between rats injected with Meth and those injected with Sal, but the former showed significantly higher Fos counts than the intact controls in all $\mathrm{CPu}$ fields studied except $\mathrm{CPu} 3$.

\section{Discussion}

Theoretically, the complex cross-over pharmacological treatment design of this study might have somewhat biased the dose-dependence of Morph- and
Meth-induced effects. However, the analgesic and cataleptic effects of Morph and Meth shown above were in agreement with the results of previous studies using less complex experimental paradigms (see $[2,9$, 40]). There was no data generated by this study that suggested that 'pretreatment' with a single dose of Morph and/or Meth influenced these effects. First, prior opioid exposure would weaken the cataleptic or antinociceptive effects of the 'challenge' opioid doses, because, with regard to these effects, pretreatment can cause (cross)tolerance but not (cross)sensitization to subsequent doses $[3,12,35]$. Second, the effects of Sal injections in the respective 'control' groups did not differ between the rats given different 'pretrea- 
tments'. Third, as we have shown in a previous study, the rats used in our experiments showed little to no sensitization or tolerance to opioid effects if the interval between consecutive drug doses was $48 \mathrm{~h}$ instead of $24 \mathrm{~h}$, despite the fact that the rats were given multiple opioid doses [36].

Meth exerted stronger procataleptic and analgesic effects than Morph. The higher potency of Meth was supported by the fact that these responses reached their respective plateaus at a Morph dose of $5 \mathrm{mg} / \mathrm{kg}$, whereas there was no plateau observed after Meth injections. Moreover, the procataleptic and antinociceptive effects were stronger after the highest Meth dose tested than after all the Morph doses tested. This observation may be relevant to the analgesic efficacy of Meth in a subset of patients showing resistance to other opioid analgetics [29].

In agreement with earlier studies assessing Fos protein [33] or c-fos mRNA expression [26], Fos-positive cell counts were low in all brain regions studied in intact controls in our study. However, high Fos proteinpositive cell counts were found in some brain structures including the S1BF, CG, AcbC and AcbSh, but not $\mathrm{CPu}$ in the Sal-'challenged' rats. These rats were previously given one dose each of Meth and Morph (see Table 1). Since even a single dose of Morph $(10 \mathrm{mg} / \mathrm{kg})$ can exert a long-lasting effect on conditioned place preference [5], it was theoretically possible that a sensitization developed from the earlier opioid doses. However, it has been shown that c-fos expression in response to Sal challenge does not differ between rats given multiple doses of Morph and Sal [14]. Furthermore, sensitization from a single Meth dose of $1 \mathrm{mg} / \mathrm{kg}$ is even less likely because pretreatment with multiple daily doses of Meth $(1 \mathrm{mg} / \mathrm{kg})$ has been found to suppress Fos protein expression (Taracha et al., unpublished observations). The most likely cause of the high Fos expression in the Sal'challenged' rats is thus experimentally induced stress. Consequently, the changes in Fos-positivity in the rats given Morph or Meth on the last day of the experiment likely represented combination effects of stress and opioid exposure. Since the rats were previously given, respectively, Meth and Morph (see Table 1), one should also consider the general ability of psychoactive drugs to induce cross-sensitization of the Fos expression response. Our earlier study indicated that this effect would only be expected in the S1JO brain region [36]. One might speculate on the possible cross-sensitization of the Fos response to Meth 'chal- lenge' in the rats injected with Morph 12 days earlier, but the existing data indicate that the Morph dose was too low to induce such a long-lasting effect [41]. Importantly, the differences in Fos protein expression between rats 'challenged' with Meth and Morph in the present study did not appear to result from possible differences in absorption of these drugs, as there was no considerable difference in the time to reach peak blood levels.

By comparing regional Fos-positive cell counts between intact controls and rats subjected both to pharmacological 'challenges' and other stressors in this study, one can identify three patterns of neuronal reactivity, as defined by effects on Fos protein expression:

(i) $C P u$. This region showed a significant increase after Morph and to a lesser extent after Meth injection, but not after Sal injection, suggesting that activation of $c$-fos expression is due to opioid exposure and not stress. The activation, which was most apparent in the dorsomedial $\mathrm{CPu}$, resembled that observed after single Morph doses in experimentally naive rats ([8, 10, 16, 17]; also observed in our laboratory), was most similar to that observed in Morph-'challenged' rats [36] because it showed increased Fos-positive cell counts in all $\mathrm{CPu}$ fields studied. Hence, it is tempting to speculate that the effect of opioids on $\mathrm{CPu}$ Fos immunostaining in this study could have been facilitated or potentiated by the stress induced by nonpharmacological procedures. This suggestion is consistent with a previous study showing that acute mild stress sensitizes the Fos response to Morph in the dorsal striatum [26]. The lack of a significant difference in $\mathrm{CPu}$ Fos immunostaining between the intact controls and the Sal group rats showed that neither the stress, nor previous exposure to opioids per se caused a similar effect.

(ii) $C G 1, C G 2, A c b C$ and AcbSh. These regions are implicated to play an essential role both in reward reinforcement and reaction to environmental 'novelty' [14, 30, 45]. Moreover, stress increases Acb dopamine release, which likely potentiates the rewarding action of psychoactive drugs [7, 22]. It is known that Acb modulates reaction(s) to painful stimuli [42], and that some psychological stimuli, e.g. novelty, can elevate Acb Fos protein levels [30]. Both Meth and Morph can elevate Fos protein in CG [34, 37]; however, Morph has also been reported to counteract the stimulatory effect of stress [26] and novelty [14]. In the present study, both CG and Acb showed significantly increased Fos-positive cell counts in Sal- or 
opioid-'challenged' rats compared to those in the intact controls, whereas there was no significant difference in these counts between the rats given Morph, Meth, or Sal. This finding, particularly with regard to Acb, conflicts with the reports of Acb Fos protein elevation after acute Morph doses [8, 17, 34]. However, the aforementioned lack of significant difference between the counts in rats given Sal and those injected with opioids can be explained by the fact that both Morph and Meth were given approximately $20 \mathrm{~min}$ prior to the stressful experimental procedures in our study. Hence, the opioids, but not Sal, could have elevated Acb Fos protein levels while preventing, through their analgesic and sedative actions, the Acb Fos response to stressful nonpharmacological stimuli. As a result, Fos expression would be similar to that in Sal-injected rats.

(iii) $S 1 B F$. This region, particularly layer IV, which is strongly activated by environmental novelty [15, 30], showed marked activation in the Sal- 'challenged' rats. No such activation was observed in their opioid'challenged' counterparts, with the exception of the S1BF layer VI in the Morph-injected rats. Morph and Meth likely attenuated this reaction via their analgesic and sedative actions. This 'inhibitory' effect was supported by negative correlations between Fos-positive cell counts in layers II/III-V and either the latency time in the hot-plate test or the duration of catalepsy. These results are in a disagreement with a report showing markedly increased activation of S1BF layer IV with simultaneous inhibition of the other S1BF layers after single heroin doses in a novel environment [30]. This conflict may result from aversive testing procedures in our experiments, and from the fact that the drug doses used by us exerted evident behavioral effects in contrast to the heroin doses used in that previous study. Notably, the S1BF activation pattern differed from that in $\mathrm{S} 1 \mathrm{JO}$, which showed only a nonsignificant trend $(p \geq 0.10)$ for stress-induced activation that was potentiated by Morph and/or Meth in most layers.

The regional patterns of $c-f o s$ activation by Meth and Morph 'challenge' doses were similar, but Meth was somewhat more effective than Morph in inhibiting S1BF Fos expression, whereas the reverse was true for the regions showing opioid-induced increases in Fos expression (e.g. in $\mathrm{CPu}$ ). Certain therapeutic advantages of Meth over Morph, such as its lower euphoric and addictive potentials, and its superior utility for normalizing molecular, cellular and physio- logical functions after long-term abuse of short-acting opiates, are attributed to the much longer half-life time of Meth. However, as shown both by this and earlier pharmacokinetic studies [1, 13, 24, 29], there are marked differences in the half-life of the opioids in rats and humans. Specifically, the Morph half-life in these species is similar, whereas for Meth the halflife is more than 10 times shorter in rats. As a result, Meth and Morph half-lives in the latter differ only by a factor of 2. This difference may have considerable implications for the biological effects of Meth in the two species, including activation of $c-f o s$ expression. In particular, one might expect 'flattening' of the differences between the effects of Morph and Meth in the rat as compared to those in humans, particularly as the two drugs are usually given via the same route ( $s c)$ to rodents, whereas opiate addicts usually take the abused opiates intravenously and Meth substitution doses are taken orally.

It is assumed that stress [21, 43], and particularly novelty [4], contribute to the development of addiction. In this regard, there are some differences between this and related reports, e.g. previous studies reported opposing effects of Morph and novelty in the CG [14] and a significant effect in the CPu of stress alone [26]. These differences are most likely due to differences in experimental stressors and in the timing of opioid and stressor administration in individual studies. However, the results from all studies (see also [30]) show considerable stress-opioid interactions in corticolimbic systems. The differences between Morphand Meth-induced Fos protein expression in this study were smaller than those found in rats with a history of previous opioid exposure [36]. These observations suggest that the most important difference between these drugs lies in their relative ability for inducing long-lasting neuroplastic changes (see [36]; also unpublished results from this laboratory).

In summary, the results of this study show that Meth, despite its markedly lower addictive potential, acts similarly to Morph in terms of its interaction with non-pharmacological stressor(s) on brain c-fos activation. These results also indicate that there is an overlap between brain regions involved in the expression of stress-induced effects and those that mediate responses to opioids. It would be interesting to determine if prolonged opioid treatment affect this combination effect, and particularly if it would differentiate between the effects of Morph and Meth. 


\section{Acknowledgments:}

The authors thank Mrs. A. Biegaj of the Institute of Psychiatry and Neurology for her excellent technical assistance. The study was supported by the Institute of Psychiatry and Neurology statutory fund \#501-03-08-065 and by the Polish Ministry of Science and Higher Education Scientific Network fund.

\section{References:}

1. Aderjan RE, Skopp C: Formation and clearance of active and inactive metabolites of opiates in humans. Ther Drug Monit, 1998, 20, 561-569.

2. Ahtee L: Catalepsy and stereotypies in rats treated with methadone: relation to striatal dopamine. Eur J Pharmacol, 1974, 27, 221-230.

3. Athanasos P, Smith CS, White JM, Somogyi AA, Bochner F, Ling W: Methadone maintenance patients are cross-tolerant to the antinociceptive effects of very high plasma morphine concentrations. Pain, 2006, 120, 267-275.

4. Badiani A, Oates MM, Robinson TE: Modulation of morphine sensitization in the rat by contextual stimuli. Psychopharmacology, 2000, 151, 273-282.

5. Bardo MT, Gehrke BJ, Shortridge BE, Rauhut AS: Effects of $\beta$-funaltrexamine and naloxonazine on singletrial morphine-conditioned place preference and locomotor activity. Pharmacol Biochem Behav, 2003, 74, 617-622.

6. Bhalla S, Matwyshyn G, Gulati A: Potentiation of morphine analgesia by BQ123, an endothelin antagonist. Peptides, 2002, 23, 1837-1845.

7. Bland ST, Twining C, Schmid MJ, Der-Avakian A, Watkins LR, Maier SF: Stress potentiation of morphineinduced dopamine efflux in the nucleus accumbens shell is dependent upon stressor uncontrollability and is mediated by the dorsal raphe nucleus. Neuroscience, 2004, 126, 705-715.

8. Bontempi B, Sharp FR: Systemic morphine-induced Fos protein in the rat striatum and nucleus accumbens is regulated by opioid receptors in the substantia nigra and ventral tegmental area. J Neurosci, 1997, 17, 8596-8612.

9. Bulka A, Plesan A, Xu XJ, Wiesenfeld-Hallin Z: Reduced tolerance to the anti-hyperalgesic effect of methadone in comparison to morphine in rat model of mononeuropathy. Pain, 2002, 95, 103-109.

10. Chang SL, Squinto SP, Harlan RE: Morphine activation of c-Fos expression in rat brain. Biochem Biophys Res Commun, 1988, 157, 698-704.

11. Dimsdale JE, Norman D, DeJardin D, Wallach MS: The effects of opioid on sleep architecture. J Clin Sleep Med, 2007, 3, 33-36.

12. Doverty M, Somogyi AA, White JM, Bochner F, Beare $\mathrm{CH}$, Menelaou A, Ling W: Methadone maintenance patients are cross-tolerant to the antinociceptive effects of morphine. Pain, 2001, 93, 155-163.

13. Eap CB, Buclin T, Baumann P: Interindividual variability of the clinical pharmacokinetics of methadone: implications for the treatment of opioid dependence. Clin Pharmacokinet, 2002, 41, 1153-1193.
14. Ferguson SM, Thomas MJ, Robinson TE: Morphineinduced c-fos mRNA expression in striatofugal circuits: modulation by dose, environmental context, and drug history. Neuropsychopharmacology, 2004, 29, 1664-1674.

15. Filipkowski RK: Inducing gene expression in barrel cortex - focus on immediate early genes. Acta Neurobiol Exp, 2000, 60, 411-418.

16. Frankel PS, Harlan RE, Garcia MM: Chronic administration of morphine alters immediate-early gene expression in the rat forebrain of post-dependent rats. Brain Res, 1999, 835, 204-212.

17. Garcia MM, Brown H, Harlan RE: Alternations in immediate-early gene proteins in the rat forebrain induced by acute morphine injection. Brain Res, 1995, 692, 23-40.

18. Gourlay GK: Advances in opioid pharmacology. Support Care Cancer, 2005, 13, 153-159.

19. He L, Whistler JL: An opiate cocktail that reduces morphine tolerance and dependence. Curr Biol, 2005, 15, 1028-1033.

20. Kreek MJ: Drug addictions. Molecular and cellular endpoints. Ann NY Acad Sci, 2001, 937, 27-49.

21. Kreek MJ, Nielsen DA, Butelman ER, LaForge KS: Genetic influences of impulsivity, risk taking, stress responsivity and vulnerability to drug abuse and addiction. Nat Neurosci, 2005, 8, 1450-1457.

22. Le Moal M, Koob GF: Drug addiction: pathways to the disease and pathophysiological perspectives. Eur Neuropsychopharmacol, 2007, 17, 377-393.

23. Lehner M, Taracha E, Skorzewska A, Maciejak P, Wislowska-Stanek A, Zienowicz M et al.: Behavioral, immunocytochemical and biochemical studies in rats differing in their sensitivity to pain. Behav Brain Res, 2006, $171,189-198$.

24. Ling GS, Umans JG, Inturrisi CE: Methadone: radioimmunoassay and pharmacokinetics in the rat. J Pharmacol Exp Ther, 1981, 217, 147-151.

25. Martin TS, Kahn W, Cholders SR: Differential regional effects of methadone maintenance compared to heroin dependence on $\mu$-opioid receptor desensitization in rat brain. Synapse, 2007, 61, 176-184.

26. Mayer P, Erdtmann-Vourliotis M, Riechert U, Ammon S, Höllt V: Mild stress sensitizes the brain's response to morphine. Mol Brain Res, 2002, 104, 143-147.

27. Mierzejewski P, Koros E, Goldberg SR, Kostowski W, Stefański R: Intravenous self-administration of morphine and cocaine: a comparative study. Pol J Pharmacol, 2003, 55, 713-726.

28. Morley JS, Makin MK: The use of methadone in cancer pain poorly responsive to other opioids. Pain Rev, 1998, $5,51-58$.

29. Nakamura K, Hachey DL, Kreek MJ, Irving CS, Klein PD: Quantitation of methadone enantiomers in humans using stable isotope-labeled $\left[{ }^{2} \mathrm{H}_{3}\right]-,\left[{ }^{2} \mathrm{H}_{5}\right]-$, and $\left.{ }^{2} \mathrm{H}_{8}\right]$ methadone. J Pharm Sci, 1982, 71, 40-43.

30. Paolone G, Conversi D, Caprioli D, Del Bianco P, Nencini P, Cabib S, Badiani A: Modulatory effect of environmental context and drug history on heroin-induced psychomotor activity and Fos protein in the rat brain. Neuropsychopharmacology, 2007, 32, 2611-2623. 
31. Paxinos G, Watson C: The Rat Brain in Stereotaxic Coordinates, 4th edn., Academic Press, San Diego, 1998.

32. Rauhala P, Idänpään-Heikkilä JJ, Tuominen RK, Männistö PT: Differential dissapearance of tolerance to thermal, hormonal and locomotor effects of morphine in the male rat. Eur J Pharmacol, 1995, 285, 69-77.

33. Sagar SM, Sharp FR, Curran T: Expression of c-fos protein in brain: metabolic mapping at the cellular level. Science, 1988, 240, 1328-1331.

34. Singh ME, Verty AN, Price I, McGregor IS, Mallet PE: Modulation of morphine-induced Fos-immunoreactivity by the cannabinoid receptor antagonist SR 141716 . Neuropharmacology, 2004, 47, 1157-1169.

35. Snow AE, Dewey WL: A comparison of antinociception induced by foot shock and morphine. J Pharmacol Exp Ther, 1983, 227, 42-50.

36. Taracha E, Chrapusta SJ, Lehner M, Skórzewska A, Maciejak P, Szyndler J, Płaźnik A: Morphine and methadone pre-exposures differently modify brain regional Fos protein expression and locomotor activity responses to morphine challenge in the rat. Drug Alcohol Depend, 2008, 97, 21-32.

37. Taracha E, Lehner M, Wisłowska-Stanek A, Zienowicz M, Maciejak P, Bidziński A, Skórzewska A et al.: Effects of methadone and morphine on c-Fos expression in the rat brain: similarities and differences. Pharmacol Rep, 2006, 58, 120-124.

38. Terpening CM, Johnson WM: Methadone as an analgesic: a review of risks and benefits. WV Med J, 2007, $103,14-18$.
39. Thomas PT, House RV, Bhargava HN: Direct cellular immunomodulation produced by diacetylmorphine (heroin) or methadone. Gen Pharmacol, 1995, 26, 123-130.

40. Tzschentke TM, Schmidt W: Morphine-induced catalepsy is augmented by NMDA receptor antagonists, but is partially attenuated by an AMPA receptor antagonist. Eur J Pharmacol, 1996, 295, 137-146.

41. Vanderschuren LJ, De Vries TJ, Wardeh G, Hogenboom FA, Schoffelmeer AN: A single exposure to morphine induces long-lasting behavioural and neurochemical sensitization in rats. Eur J Neurosci, 2001, 14, 1533-1538.

42. Xiong W, Yu LC: Involvement of mu- and kappa-opioid receptors in morphine-induced antinociception in the nucleus accumbens of rats. Neurosci Lett, 2006, 399, 167-170.

43. Zhu H, Lee MS, Agatsuma S, Hiroi N: Pleiotropic impact of constitutive fos $\mathrm{B}$ inactivation on nicotine-induced behavioral alterations and stress-related traits in mice. Hum Mol Gen, 2007, 16, 820-836.

44. Zienowicz M, Wisłowska-Stanek A, Lehner M, Taracha E, Maciejak P, Sobolewska A, Szyndler J et al.: Fluoxetine-induced anxiety and nervousness. Pharmacol Rep, 2006, 58, 115-119.

45. Zubieta JK, Smith YR, Bueller JA, Xu Y, Kilbourn MR, Jewett DM, Meyer CR et al.: Regional mu receptor regulation of sensory and affective dimensions of pain. Science, 2001, 293, 311-315.

Received:

June 19, 2008; in revised form: April 1, 2009 